\title{
$\checkmark$ DESCRIPTION
}

\section{D'UN \\ POISSON AVEUGLE \\ découvert par M. G. GEERTS \\ dans la grotte de Thysville (Bas-Congo) \\ PAR}

\section{G. $=$ A. BOULENGIER}

La découverte de M. Geerts est d'un grand intérêt, car on ne connaissait encore que fort peu de poissons d'eau douce aveugles et aucun d'Afrique ni de la famille des Cyprinides, à laquelle appartient le genre nouveau que j'ai le plaisir de décrire ici sous le nom de

\section{Cæcobarbus, g. n.}

Se distingue du genre Barbus par l'absence complète des yeux, qu'on ne trouve pas mème en soulevant la peau. Les écailles, très minces et molles, ne montrent aucune striation, ce qui empêche de rattacher ce poisson à une section particulière du genre Barbus et, par conséquent, de se prononcer sur sa dérivation directe; elles sont pourvues de petits pores, plus ou moins nombreux, qui sont évidemment des organes sensoriels, qu'on observe également sur la tête. La ligne latérale est normalement développée, à tubes longs et droits.

\section{Cæcobarbus Geertsii, sp. n.}

Corps comprimé, sa largeur $\mathrm{I}^{\mathrm{I}} / 2$ à 2 fois dans sa hauteur, qui est comprise $4 \%$ à $4 \%$ fois dans la longueur totale; longueur de la tête $3 \frac{3}{4}$ à 4 fois dans celle-ci. Museau arrondi, depassant peu la bouche, arquée en croissant, dont les lèvres sont médiocrement développées et interrompues au menton; deux 
barbillons de chaque côté, le postérieur un peu plus long que l'antérieur, mesurant à peu près les ${ }^{2} / 5$ de la longueur de la tête. Dorsale III $7-8$, à égale distance des narines et de la racine de la caudale, à bord très faiblement échancré, le plus long rayon mesurant les ${ }^{4 / 5}$ de la longueur de la tête; troisième rayon simple ossifié, mais peu épais. Anale III 5, n'atteignant pas la caudale. Pectorale plus courte que la tête, atteignant la base de la ventrale, qui correspond à l'origine de la dorsale. Caudale profondément échancrée. Pédicule caudal deux fois aussi long que haut. Écailles $28-29 \frac{4^{\mathrm{T}} / 2}{5^{\mathrm{x}} / 2}, 3$ entre la ligne latérale et la ventrale, 12 autour du pédicule caudal. Pigmentation nulle, le poisson étant blanc à l'état vivant.

Longueur totale : 75 millimètres.

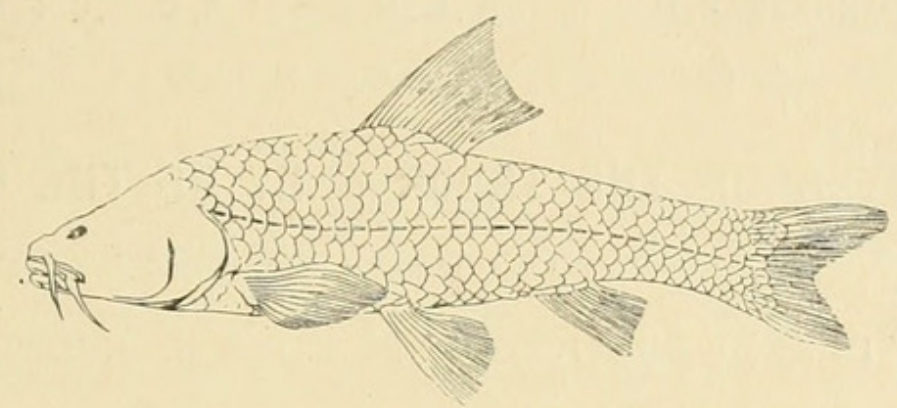

Trois adultes et un jeune, donnés au Musée du Congo belge par M. G. Geerts, qui a bien voulu me fournir les renseignements suivants sur son importante découverte :

Les poissons ont été pêchés à la main, dans le lac de la grotte de Thysville, en saison sèche.

La grotte se trouve vers la côte 700 mètres au-dessus du niveau de la mer, à 3 kilomètres du col de Thysville, où passe la ligne du chemin de fer du Bas-Congo.

Le terrain appartient à la zone schisto-calcaire du bassin calcaire du Bas-Congo (voir Delhaye et Sluys, Les Calcaires du BasCongo, revue "Congo », $2^{e}$ année, t. I, février I92 I).

Longueur attribuée à la grotte : 500 à 600 mètres.

Longueur approximative du lac en saison sèche : 50 mètres.

Section moyenne approximative : $4 \times 4$ mètres.

L'entrée de la grotte se trouve dans le fond d'une vallée, les eaux de ruissellement s'y engouffrent pendant la saison des pluies. 


\section{$2 \mathrm{BHL}$ Biodiversity Heritage Library}

Boulenger, George-Albert. 1921. "Description d'un poisson aveugle découvert par M. G. Geerts dans la grotte de Thysville (Bas-Congo)." Revue zoologique africaine 9, 252-253. https://doi.org/10.5962/bhl.part.24481.

View This Item Online: https://www.biodiversitylibrary.org/item/42138

DOI: https://doi.org/10.5962/bhl.part.24481

Permalink: https://www.biodiversitylibrary.org/partpdf/24481

\section{Holding Institution}

American Museum of Natural History Library

\section{Sponsored by}

Biodiversity Heritage Library

\section{Copyright \& Reuse}

Copyright Status: NOT_IN_COPYRIGHT

This document was created from content at the Biodiversity Heritage Library, the world's largest open access digital library for biodiversity literature and archives. Visit BHL at https://www.biodiversitylibrary.org. 